\title{
Does shock modifiability contribute to preference for signaled shock?
}

\author{
PIETRO BADIA and BRUCE ABBOTT \\ Bowling Green State University, Bowling Green, Ohio 43403
}

\begin{abstract}
The central question asked was whether differential shock modification occurs (posturally induced differences in shock contact time) under signaled and unsignaled conditions using scrambled shock. Shock modifiability was tested with two different shock sources, intensities, and scrambling units by measuring the duration of time subjects were in contact with shock. Subjects were then given a choice between the signaled and unsignaled conditions. Results showed that differential modification of shock contact time did not occur between signaled and unsignaled conditions with any shock source, intensity, or scrambler unit. In addition, subjects preferred the signaled condition. It was concluded that experiments using scrambled shock are not confounded by posturally induced differences in shock contact time.
\end{abstract}

We have recently completed an extensive review of the research related to predictable and unpredictable shock situations (Badia, Harsh, \& Abbott, 1979). Our review allowed us to draw a number of firm conclusions. A few of these are that: (1) rats, whether albino or hooded, male or female, prefer predictable over unpredictable shock conditions; (2) preference for the predictable condition occurs whether shock is scrambled or unscrambled; and (3) the predictable condition is preferred with different shock delivery systems.

In spite of these extensive findings, criticism of the fundamental data base has persisted (e.g., Biederman \& Furedy, 1973, 1976; Furedy \& Biederman, 1976; Marlin, Berk, \& Miller, 1978). A major issue is the degree to which previous findings may be affected by the method used to deliver shock. According to these authors, the method of delivering shock through floor grids permits subjects to make skeletal-muscular responses on the grid which serve to reduce the aversiveness of the shock. Presumably these responses are more effectively executed when signals precede shock than when signals are absent. If this is so, then subjects receive less severe shocks in the signaled condition than they do in the unsignaled one.

According to Furedy and Biederman (1976), "shock modification" accounts entirely for the observed preference for the signaled condition. To support this view, they provided data showing a correlation between reduction in the average amount of cur-

This research was supported in part by Grant 33725 from the National Science Foundation and the Faculty Research Committee of Bowling Green State University. Reprints may be obtained from Pietro Badia, Department of Psychology, Bowling Green State University, Bowling Green, Ohio 43403. B. Abbott is now at Indiana University-Purdue University at Fort Wayne. rent flowing through an animal during shock and the degree of preference for the signaled condition. This relationship was observed only when shock was unscrambled; when shock was scrambled, neither modification nor preference for the signaled condition occurred. These findings suggested to Furedy and Biederman that preference for the signaled condition emerges only when shock is modifiable.

A difficult problem for this view is that many studies have found strong preference for the signaled condition when shock was either scrambled or delivered through surface electrodes (e.g., Badia \& Culbertson, 1972; Badia, Harsh, Coker, \& Abbott, 1976; Harsh \& Badia, 1975, 1976; Miller, Daniel, \& Berk, 1974; Miller, Marlin, \& Berk, 1977; Safarjan \& D'Amato, 1978). These studies indicate that preference for signaled shock does not depend on overt modification of shock. Recently, however, circumstantial evidence has been provided apparently implicating shock modification in studies using scrambled grid shock (Marlin et al., 1978). Marlin et al. observed rat postures both during the signal and during the intershock interval of a signaled shock condition. Postural adjustments (rearing) were observed more frequently during the signal with grid shock, but no differences were observed with tailshock. These authors argue that postural changes modify shock and thus contribute to preference for the signaled condition. While acknowledging that preference for signaled shock does not depend primarily upon modification, Marlin et al. (1978) asserted that scrambled grid shock fails to exclude trivial explanations of preference for signaled shock and therefore should not be used.

This is a harsh conclusion. Its acceptance renders questionable a great deal of the existing literature on preference for signaled shock, for much of the data was gathered using scrambled shock (see Badia et al., 
1979, for a review). Moreover, it excludes use of scrambled shock in future research in favor of technically more difficult and cumbersome surface electrodes, which themselves may create problems through detachment, corrosion, deterioration of the skin or tail (in long studies), or by distraction of the subject from the experimental contingencies. In view of these consequences, it is important to determine whether modification of scrambled grid shock does, in fact, contribute to preference for signaled shock. It is in this regard that the data supplied by Marlin et al. provide only circumstantial evidence. The fact that different postures were observed during the signal and during the intershock interval does not necessarily indicate that subjects had learned to modify shock. Alternative explanations for the different postures can be advanced that do not imply differential shock modification, for example, classically conditioned responses to the signal. To answer the question properly, actual duration of contact with shock should be measured under both signaled and unsignaled conditions and these durations compared. The studies reported here do this.

Several experiments were designed to determine whether modification of scrambled grid shock occurred and, if so, whether modification occurred differentially under predictable and unpredictable conditions. An electronic circuit was developed to allow monitoring the duration of time subjects received shock. The shock modifiability notion was tested with two different shock sources (BRS constant wattage and Lehigh Valley constant current); with the BRS source, two shock intensities were used. Alternating sessions of predictable and unpredictable shock were given using parameter values previously used to study preference. In addition, subjects were given a choice between predictable and unpredictable conditions.

\section{EXPERIMENT 1}

\section{Method}

Subjects. Twelve naive female Sprague-Dawley (Holtzman Co.) rats, 90-120 days old at the start of the experiment, served as subjects. They were maintained between sessions in individual cages and had continuous access to food and water. A reversed 12-h light-dark cycle was in effect.

Apparatus. Experiments were conducted in an operant conditioning chamber housed in a sound-attenuating box. Ventilation and background noise $(65 \mathrm{~dB})$ were provided by a 75 CFM blower. The chamber was $22.9 \mathrm{~cm}$ wide $\times 23.5 \mathrm{~cm}$ deep $\times 24.1 \mathrm{~cm}$ high, as measured from the surface of the grid floor. The rear and side walls were aluminum; the ceiling and door (front wall) were Plexiglas. A Plexiglas false ceiling, mounted $11.4 \mathrm{~cm}$ above the floor, was installed to reduce the incidence of unauthorized avoidance.

One panel (right wall) contained two Gerbrands rat levers (Model G 6312) mounted $4.4 \mathrm{~cm}$ above the floor, two cue lights (No. $31328-\mathrm{V}$ dc bulbs covered by $13-\mathrm{cm}$ white jeweled lens caps) mounted $14.3 \mathrm{~cm}$ above the floor, and two houselights $(509 \mathrm{~K}$ $28-\mathrm{V}$ dc bulbs covered by $2.5-\mathrm{cm}$ white jeweled lens caps) mounted $21.6 \mathrm{~cm}$ above the floor. All were centered $6.0 \mathrm{~cm}$ from the left wall edge. The left cue light and right houselight were not used in the experiment. A 7.6-cm-diam, 8-8 speaker, centered between the four lights, provided the outlet for $1,000-\mathrm{Hz}, 86-\mathrm{dB}$ tone signals. The floor consisted of $12.64-\mathrm{cm}$-diam stainless steel rods spaced $1.91 \mathrm{~cm}$ center-to-center. The Plexiglas end plates holding the rods were mounted $1.3 \mathrm{~cm}$ beyond the chamber walls to minimize contamination. Shock $(.5 \mathrm{sec}, 75 \mathrm{~mW})$ was generated by a BRS SGS001 constant-wattage shocker with nine independent electronically scrambled outputs. This is the same unit used in several published experiments on preference for signaled shock (e.g., Badia, Culbertson, \& Harsh, 1973; Badia, Harsh, Coker, \& Abbott, 1976). Grid bars 1 and 12,2 and 10 , and 3 and 11 were electrically paired to accommodate mating the 12 grid bars to the 9 scrambler outputs.

An electronic circuit, which detected current flow through the subjects, was constructed as follows: One NE-2 neon bulb was placed in series with each of the nine outputs. Each bulb glowed only when the subject completed the circuit between it and an opposite-polarity line. A phototransistor-amplifier circuit for each bulb produced an output whenever the bulb lighted. The nine outputs were fed through a BRS OR-gate. The output of the OR-gate enabled a $1,000-\mathrm{Hz}$ precision clock (BRS MV-4S), which counted into a set of registers. At the end of each shock, the contents of the registers were output onto paper tape and the registers were cleared. Thus, each record contained the total time in milliseconds during a shock that current flowed through the subject. At times, the output of the detection circuit was also fed to an oscilloscope and the resulting display was photographed. The response time of the detector was sufficient to resolve the individual pulses of the $50-\mathrm{Hz}$ scrambler and shock contacts as short as $1 \mathrm{msec}$. A solidstate system programmed the experimental contingencies.

Procedure. The subjects were run in 6-h sessions on alternate days. Termination of the right cue light indicated the start of each session. Shock in all conditions was $.5 \mathrm{sec}$ and $75 \mathrm{~mW}$, and was delivered at all times according to a variable-time 120 -sec schedule based on the Fleshler and Hoffman (1962) progression modified for an 8-sec minimum intershock interval. In the signaled condition, each shock was preceded by a $5-\mathrm{sec}$ tone signal, which terminated with shock onset. In the unsignaled condition, no signals were programmed. Correlated stimuli identified the condition in effect. Light (left houselight on) and darkness (light off) identified the signaled and unsignaled conditions for half the subjects; for the others, the reverse was true.

Six subjects received two sessions of signaled and two of unsignaled shock in alternation, with order of conditions and correlated stimuli counterbalanced (training). During training, responses on the levers had no scheduled consequences, but the responses and the time that would have been spent in the signaled condition had these responses been effective were recorded. Following training, the subjects were placed in the unsignaled condition and given the opportunity to change to the signaled condition (changeover). Each response in the unsignaled condition produced $1 \mathrm{~min}$ in the signaled condition; responses in the signaled condition had no programmed consequences. A 2 -sec changeover delay prevented changeovers from occurring during and immediately following shock.

The subjects remained in the changeover phases until the percent time spent in changeover stabilized to within $10 \%$ across three consecutive sessions. They were then placed in training until they had again met the criterion. Finally, a second changeover phase was given until stability was again reached. Six additional subjects were run with a lower shock intensity of $.5 \mathrm{~mW}$. These subjects were given the training condition for 10 sessions and the changeover condition for 20 .

\section{Results and Discussion}

Figure 1 displays data for the six subjects receiving $75 \mathrm{~mW}$ of shock. This figure contains data showing the duration of grid contact time during the initial training phase $(12 \mathrm{~h}$ of signaled shock and $12 \mathrm{~h}$ of unsignaled shock using 6-h sessions) and also during 
the second training phase. As shown in Figure 1, the duration of shock received under the signaled and unsignaled condition is virtually identical across both training phases (replication 1 and replication 2). The preference data are shown in Figure 2. During the first sessions in which the subjects were given a choice, five of the six subjects changed to the signaled condition; the one exception was PR-19. The subjects were then placed back into training for a minimum of eight 6-h sessions, during which signaled and unsignaled conditions alternated. Then the subjects were again given a choice. This time all subjects changed to the signaled condition (Figure 2). To avoid confusion, it should be noted that Figure 1 contains data concerning shock duration only during the two training phases. Contact times were also recorded during the changeover phases, and they show the same trend. However, these data tend to be less reliable than those collected during the training phases (because subjects infrequently sampled the unsignaled condition during changeover) and therefore are not presented in the figure.

Figure 3 displays data for the six subjects receiving $.5 \mathrm{~mW}$ of signaled and unsignaled shock across 10 6-h sessions. Again, it is very clear that the duration of contact with the electrified grid is essentially the same for both conditions. No differential trends in the duration of grid contact time is apparent even after as many as $60 \mathrm{~h}$ of shock occurring 30 times per
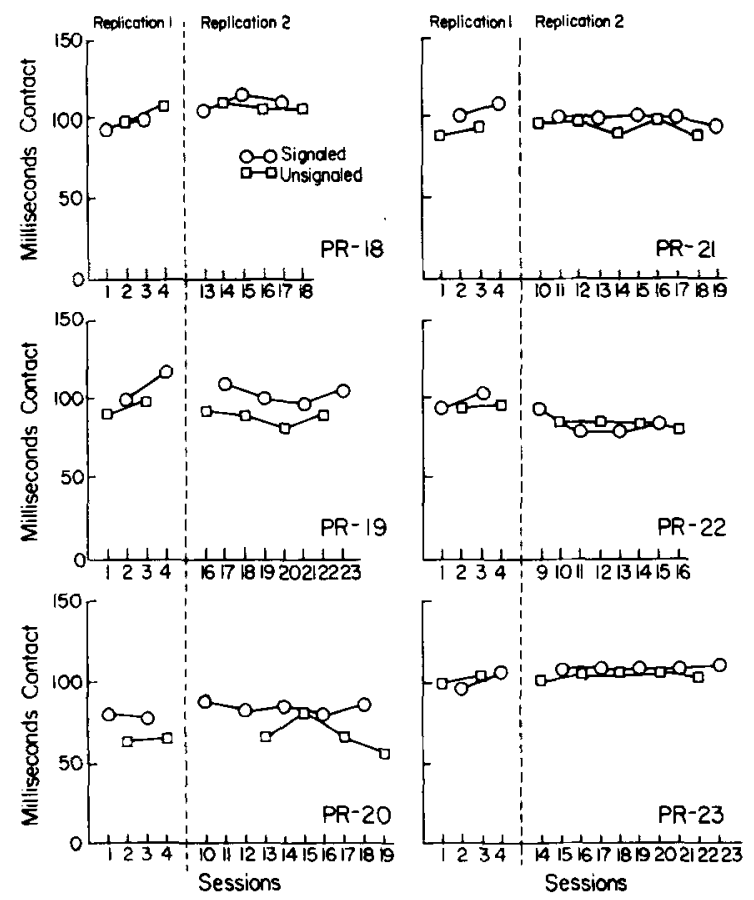

Figure 1. Duration of grid contact time during shock for the six subjects receiving $75 \mathrm{~mW}$ of signaled and unsignaled shock (BRS constant wattage). The gap in sessions between the first and second phases reflects those session in which preference testing occurred.
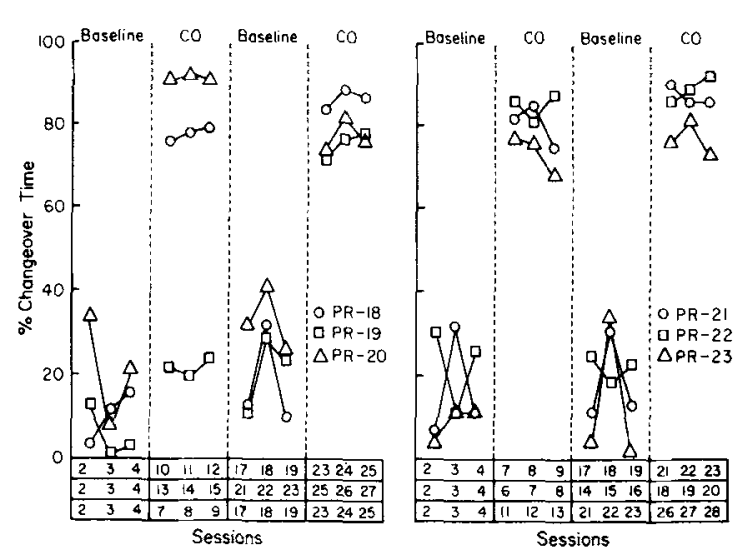

Figure 2. Data on preference are displayed showing the percent of time spent in the signaled condition (shock intensity was $75 \mathrm{~mW}$ ).
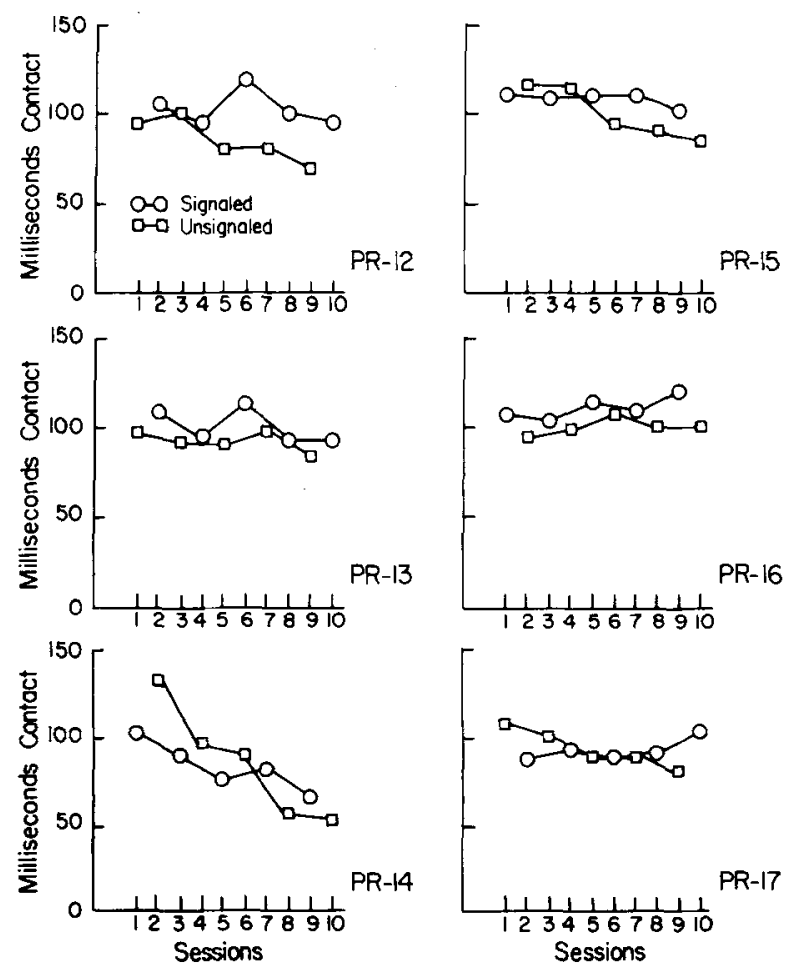

Figure 3. Data are displayed showing the duration of grid contact during shock for the six subjects receiving $50 \mathrm{~mW}$ of signaled and unsignaled shock.

hour. Figure 4 displays the choice data for these subjects. Preference for the signaled condition again emerged. However, relative to the subjects receiving $75 \mathrm{~mW}$ of shock, the subjects receiving $50 \mathrm{~mW}$ required more sessions to display this preference and the levels attained tended to be somewhat lower. This weakened preference at lower shock intensities is consistent with previous findings (e.g., Harsh \& Badia, 1975). 


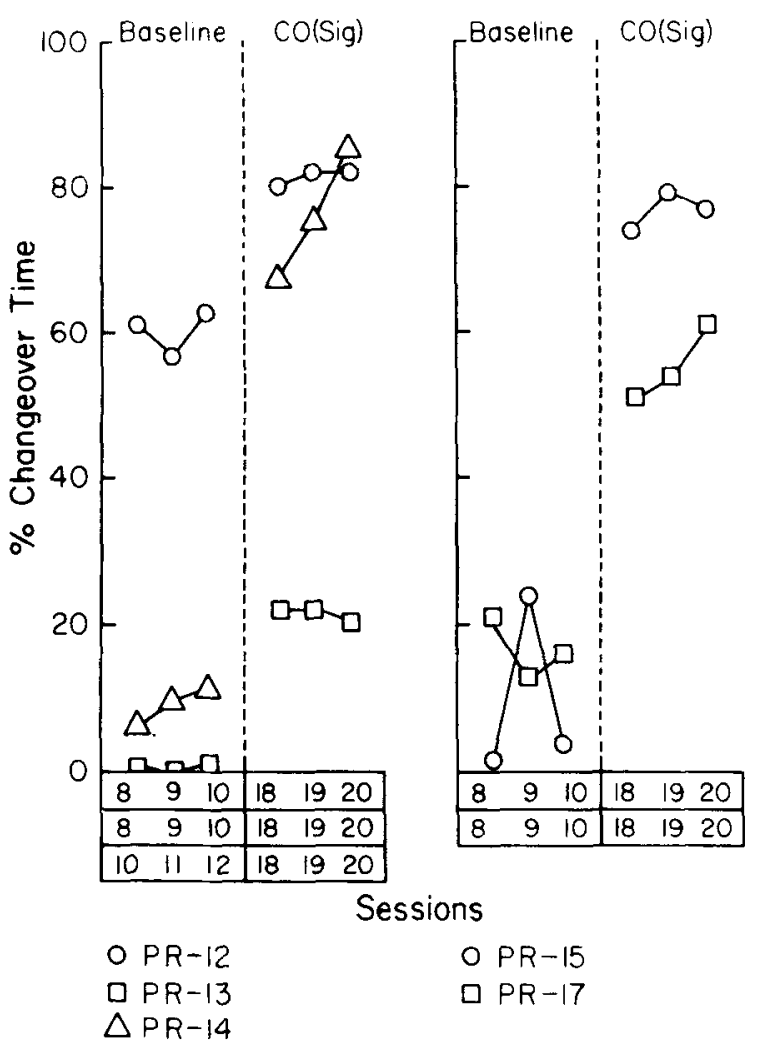

Figure 4. Data on preference are displayed showing the percent of time spent in the signaled condition with $50 \mathrm{~mW}$ of shock.

While it is clear from these data that differential modification of shock contact time did not occur, the figures do reveal some degree of reduction in absolute contact time. Since the scrambling rate was $\mathbf{5 0}$ lines/sec and there were nine independent lines, then for a .5-sec shock the maximum duration for an animal standing on two grids would be $110 \mathrm{msec}$. (Durations longer than $110 \mathrm{msec}$ are possible if the subject is in contact with more than two grids at one time.) As shown in Figures 1 and 3, actual contact times generally fell somewhat below this value. While $100 \mathrm{msec}$ was typical, two subjects (PR-20 and PR-14) managed to reduce contact time to about $60 \mathrm{msec}$. Visual observation revealed that the subjects were accomplishing this reduction by running and leaping during shock. Similar behavior occurred whether shock was signaled or unsignaled.

\section{EXPERIMENT 2}

Experiment 1 demonstrated that under conditions frequently employed in previous experiments on preference for signaled shock, differential modification of shock contact time does not occur. These results were obtained with electronically scrambled constant-wattage shock. However, many studies have employed constant-current shock, often in conjunc- tion with a mechanical scrambler. It may be argued that while present results rule out differential modification where constant-wattage shockers and/or electronic scramblers were used, they do not rule out differential modification where constant-current shockers and/or mechanical scramblers were used. Experiment 2 examined modification of shock in the signaled and unsignaled conditions with constantcurrent, mechanically scrambled shock.

\section{Method}

Subjects. Four naive female rats similar to those used in Experiment 1 were used.

Apparatus. A chamber similar to the one described in Experiment 1 was used. Shock $(1.0 \mathrm{~mA})$ was generated by a 24 -line Lehigh Valley 1531 constant-current shocker-scrambler and delivered to the grid floor, walls, and levers (13 lines used). The electro. mechanical programmer was located in an adjacent room.

A different current-detection circuit was required by the different shocker-scrambler. A $30-k \Omega$ resistor was spliced in series between one of the shocker outputs and scrambler inputs. The voltage drop across this resistor was directly proportional to the current flow through the subject. A Schmidt trigger (BRS ST 202) produced an output whenever current flow exceeded $.1 \mathrm{~mA} \mathrm{(4} \mathrm{V}$ dc drop), a value considerably below that necessary to sustain preference for signaled shock (Harsh \& Badia, 1975). This output was fed to the clock circuit previously described.

Procedure. The subjects were exposed on alternating sessions to the signaled and unsignaled conditions described in Experiment 1. Subjects PR-1 and PR-4 received the signaled condition first. Subjects PR-2 and PR-3 received the unsignaled condition first. Light and darkness identified the signaled and unsignaled conditions, respectively, for Subjects PR-1 and PR-2; for Subjects PR-3 and $P R-4$, the reverse was true. The subjects were trained for 8 6-h sessions (training for Subject PR-3 was extended to 10 sessions).

\section{Results}

Figure 5 displays the data from four subjects for the Lehigh Valley constant-current shock source (1.0 $\mathrm{mA})$ under signaled and unsignaled conditions.
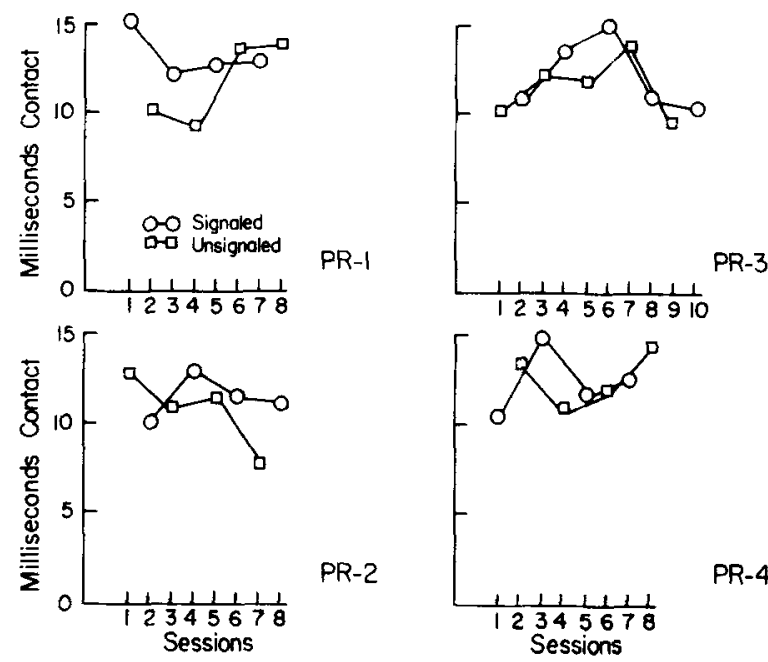

Figure 5. Data are displayed showing the duration of grid contact during shock for the four subjects receiving $1.0 \mathrm{~mA}$ constant current shock (Lehigh Valley) under signaled and unsignaled conditions. 
It is clear from these data that contact with the electrified grid bars is essentially the same under both conditions and over many sessions. Comparing the results of Experiments 1 and 2, it is apparent that shock contact times in the latter study were about $1 / 10$ th as great as those in the former. These differences reflect a greater ratio of "off" to "on" time produced by the mechanical scrambler of Experiment 2 and do not indicate any changes in the behavior of the subjects during shock. Allowing for the differences in total contact time, the behavior of subjects in the two experiments is remarkably similar.

\section{DISCUSSION}

Marlin et al. (1978) have argued strongly against delivering shock through floor grids when testing preferences for signaled over unsignaled shock. This argument is based on the assumption that rearing postures observed during signals when grid shock was employed serve to attenuate the shock. The present results do not support this argument. They indicate that contact shock is the same whether shock is signaled or unsignaled. These findings occurred whether shock was generated by a constant wattage source (Experiment 1) or by a constant current one (Experiment 2), and whether shock was relatively strong $(75 \mathrm{~mW})$ or relatively weak $(50 \mathrm{~mW})$. It is therefore likely that the present results have considerable generality. Further data showed that preference for the signaled condition occurred despite the absence of differential shock modification, a finding that comes as no surprise in view of similar results obtained with tailshock (e.g., Miller, Daniel, \& Berk, 1974), ear clips (Perkins, Seymann, Levis, \& Spencer, 1966), and water electrodes (Fisher \& Badia, 1975).

Some may challenge the conclusion that shock modification did not occur in the present study on grounds that shock contact time is not an appropriate measure of shock modification. This argument would maintain that subjects could modify shock aversiveness (e.g., by regulating current flow or surface area in contact with the grid) without altering the duration of shock contact. However, while this argument is appealing, it is not supported by our visual observations, which revealed a rapid makebreak pattern of shock contact resulting from shockelicited running and leaping. These responses serve to keep the subject off the grid during some portion of the shock and thus tend to reduce shock contact time; they do not permit the precise regulation of current flow or contact area postulated by the differential modification hypothesis. Indeed, when running occurs, measures integrating current flow over time (e.g., Furedy \& Biederman, 1976) are likely to reflect primarily changes in contact time rather than current density. Since running was the response to shock in the present study, it follows that shock contact time was an appropriate measure of shock modification.

The present findings permit the following conclusions: (1) Scrambled grid shock does not produce differential modification of signaled and unsignaled shock as reflected by shock contact time. Therefore, (2) previous studies in this area using scrambled shock, whatever other problems they may suffer, do not appear to be confounded by posturally induced differences in the aversiveness of signaled and unsignaled shocks. (3) There is no compelling reason to switch from scrambled grid shock to tailshock in future research of this type. Since tailshock can introduce new problems, such as unreliability of fixedelectrode preparations over long testing periods and distracting effects on the animal, there is good reason to continue using scrambled shock in the future.

\section{REFERENCES}

Badia, P., \& Culbertson, S. The relative aversiveness of signaled vs. unsignaled escapable and inescapable shock. Journal of the Experimental Analysis of Behavior, 1972, 17, 463-471.

Badia, P., Culbertson, S., \& Harsh, J. Choice of longer or stronger signaled shock over shorter or weaker unsignaled shock. Journal of the Experimental Analysis of Behavior, 1973, 19, 25-33.

Badia, P., Harsh, J., \& Abbott, B. Choosing between predictable and unpredictable shock conditions: Data and theory. Psychological Bulletin, 1979, 86, 1107-1131.

Badia, P., Harsh, J., Coker, C. C., \& Abbott, B. Choice and the dependability of stimuli that predict shock and safety. Journal of the Experimental Analysis of Behavior, 1976, 26, 95-111.

Biederman, G. B., \& Furedy, J. H. Preference of signaled shock phenomenon: Effects of shock modifiability and light reinforcement. Journal of Experimental Psychology, 1973, 100, 380-386.

Biederman, G. B., \& Furedy, J. J. The preference for signaled shock phenomenon: Fifty days with scrambled shock in the shuttlebox. Bulletin of the Psychonomic Society, 1976, 7, 129-132.

Fisher, C., \& Badia, P. Preference for signaled or unsignaled shock in goldfish. Bulletin of the Psychonomic Society, 1975, 6, 195-197.

Fleshler, N., \& Hoffman, H. S. A progression for generating variable interval schedules. Journal of the Experimental Analysis of Behavior, 1962, 5, 529-530.

Furedy, J. J., \& Binerman, G. B. Perference for signaled shock phenomenon: Direct and indirect evidence for modifiability factors in the shuttlebox. Animal Learning \& Behavior, 1976, $4,1-5$.

HaRsh, J., \& Badia, P. Choice for signalled over unsignalled shock as a function of shock intensity. Journal of the Experimental Analysis of Behavior, 1975, 23, 349-355.

HARSH, J., \& BADiA, P. A temporal parameter influencing choice between signalled and unsignalled shock schedules. Journal of the Experimental Analysis of Behavior, 1976, 25, 327-333. 
Marlin, N. A., Berk, A. M., \& Millen, R. R. Modification and avoidance of unmodifiable and unavoidable footshock. Bulletin of the Psychonomic Society, 1978, 11, 203-205.

Miller, R. R., Daniel, D., \& BERK, A. M. Successive reversals of a discriminated preference for signaled tailshock. Animal Learning \& Behavior, 1974, 2, 271-274.

Miller, R. R., Marlin, N. A., \& Berk, A. M. Reliability and sources of control of preference for signaled shock. Animal Learning \& Behavior, 1977, 5, 303-308.

Perkins, C. C., Jr., Seymann, R. G., Levis, D. J., \& Spencer, H. R., JR. Factors affecting preference for signal-shock over shock-signal. Journal of Experimental Psychology, 1966, 72, 190-196.

Safarjan, W. R., \& D'Amato, M. R. Variables affecting preference for signaled shock in a symmetrical changeover design. Learning and Motivation, 1978, 9, 314-331.

(Received for publication February 23, 2979; revision accepted June 9, 1979.) 